\title{
Characterization of Eubacterium coprostanoligenes sp. nov., a Cholesterol-Reducing Anaerobe $\dagger$
}

\author{
TIMOTHY A. FREIER, ${ }^{1} \neq$ DONALD C. BEITZ, ${ }^{2}$ LING LI, ${ }^{2}$ AND PAUL A. HARTMAN ${ }^{1 *}$ \\ Department of Microbiology, Immunology and Preventive Medicine, ${ }^{1}$ and \\ Department of Animal Science, ${ }^{2}$ Iowa State University, Ames, Iowa 50011
}

\begin{abstract}
A small, anaerobic, gram-positive coccobacillus that reduces cholesterol to coprostanol was isolated from a hog sewage lagoon. This isolate, strain $\mathrm{HL}^{\mathrm{T}}(\mathrm{T}=$ type strain) does not require cholesterol for growth, but it requires lecithin and has phospholipase activity. Much acid is produced by the fermentation of amygdalin, lactose, and salicin. Arabinose, cellobiose, fructose, glucose, mannose, and melibiose are fermented weakly. Acetic, formic, and succinic acids are produced, as is hydrogen. The isolate does not reduce nitrate, produce indole, or hydrolyze starch and gelatin. Esculin is hydrolyzed. The properties of strain HL $^{\mathrm{T}}$ are most similar to those of members of the genus Eubacterium. Because strain HL (= ATCC 51222) has unique morphological and physiological properties, we propose that it should be the type strain of a new species in the genus Eubacterium, Eubacterium coprostanoligenes.
\end{abstract}

To date, 13 strains of cholesterol-reducing bacteria have been isolated and characterized $(2,4,12,14)$. All of these organisms were isolated from the fecal contents of rats, humans, or baboons and were classified as strains of Eubacterium species.

Because of the methods used and the sources sampled, most of the strains of cholesterol-reducing bacteria that have been characterized have similar properties. These bacteria require strict anaerobic conditions for growth, and all but two strains require a plasmalogen (plasmenylethanolamine) to reduce cholesterol to coprostanol (1). Many also require cholesterol or a related sterol for growth $(4,12,14)$.

Coprostanol is not absorbed by the human gastrointestinal system. Therefore, the use of bacteria that can convert cholesterol to coprostanol holds promise for medical reasons and is of interest to food industries. New methods and a wide range of sample types have been tested to facilitate the isolation of new cholesterol-reducing bacteria $(5,6)$. In this paper, we describe characterization of a cholesterol-reducing bacterium isolated from a hog sewage lagoon. Because strain HL has unique morphological and physiological properties, including the capacity to reduce cholesterol to coprostanol, we propose that it should be the type strain of a new species, Eubacterium coprostanoligenes.

\section{MATERIALS AND METHODS}

Media and culture conditions. Base cholesterol medium (BCM) contained (per liter) $2 \mathrm{~g}$ of Casitone (Difco Laboratories, Detroit, Mich.), $10 \mathrm{~g}$ of yeast extract, $2 \mathrm{~g}$ of cholesterol (ash-free; Sigma Chemical Co., St. Louis, Mo.), $1 \mathrm{~g}$ of lecithin (type IV-S; Sigma), $0.5 \mathrm{~g}$ of sodium thioglycolate, 1 $\mathrm{g}$ of $\mathrm{CaCl}_{2} \cdot 2 \mathrm{H}_{2} \mathrm{O}$, and $1 \mathrm{mg}$ of resazurin. Plasmenylethanolamine was not added to this medium. BCM was prepared

\footnotetext{
* Corresponding author. Mailing address: Department of Microbiology, Immunology and Preventive Medicine, 205 Science I, Iowa State University, Ames, IA 50011-3211.

† Iowa Agriculture and Home Economics Experiment Station Journal Paper no. J-15152.

$\doteqdot$ Present address: Cargill Analytical Services, Cedar Rapids, IA 52401-2153.
}

as described by Brinkley and coworkers (1), with the following modifications: cholesterol and lecithin were homogenized in distilled, purified water in a Waring blender under a stream of $\mathrm{O}_{2}$-free $\mathrm{N}_{2}$ gas (7); other components were added; and the $\mathrm{pH}$ was adjusted to 7.2 with $3 \mathrm{~N} \mathrm{KOH}$. The medium was boiled under an $\mathrm{N}_{2}$ atmosphere and cooled, and 9-ml aliquots were dispensed into culture tubes (16 by $100 \mathrm{~mm}$ ). The tubes were sealed with butyl rubber stoppers, placed in a press, and sterilized in an autoclave at $121^{\circ} \mathrm{C}$ for $15 \mathrm{~min}$. After sterilization, the press was inverted several times while it cooled to keep the lipids dispersed in the tubes.

The medium used for biochemical characterization was similar to that of Brinkley et al. (1) and contained the same components as BCM, as well as $40 \mathrm{mg}$ of $\mathrm{K}_{2} \mathrm{HPO}_{4}$ per liter and $40 \mathrm{mg}$ of $\mathrm{KH}_{2} \mathrm{PO}_{4}$ per liter. This medium was prepared, reduced, dispensed, and sterilized as described above for BCM; the medium was dispensed ( $4 \mathrm{ml}$ per tube) into tubes that were 13 by $100 \mathrm{~mm}$.

Nitrate reduction was determined by using a medium containing (per liter) $3 \mathrm{~g}$ of beef extract (Difco), $5 \mathrm{~g}$ of peptone (Difco), $1 \mathrm{~g}$ of $\mathrm{KNO}_{3}, 1 \mathrm{~g}$ of lecithin, and $2 \mathrm{~g}$ of cholesterol. The lecithin and cholesterol were mixed and homogenized, and the medium was prepared as described above for BCM. To test for growth (cholesterol reduction), portions of nitrate reduction medium inoculated with strain $\mathrm{HL}^{\mathrm{T}}$ ( $\mathrm{T}=$ type strain) and incubated for 3 days at $37^{\circ} \mathrm{C}$ were extracted, and the sterols were separated by thin-layer chromatography (TLC) as described by Freier (5).

A modified lecithin agar medium (MLA) similar in formulation to the lecithin agar described by Chrisope et al. (3) was prepared in the same way that lecithin agar was prepared, except that fraction A contained $3 \mathrm{~g}$ of lecithin, $6 \mathrm{~g}$ of cholesterol, and $135 \mathrm{ml}$ of distilled, purified water and was homogenized in a Waring blender for $10 \mathrm{~min}$. Fraction B contained $3 \mathrm{~g}$ of Casitone, $3 \mathrm{~g}$ of yeast extract, $5.4 \mathrm{~g}$ of BiTec agar (Difco), $30 \mathrm{mg}$ of trypan blue, and $150 \mathrm{ml}$ of distilled, purified water. The $\mathrm{pH}$ of fraction $\mathrm{B}$ was adjusted to 7.2. Fraction $\mathrm{C}$ contained $0.3 \mathrm{~g}$ of $\mathrm{CaCl}_{2} \cdot 2 \mathrm{H}_{2} \mathrm{O}$ dissolved in 15 $\mathrm{ml}$ of distilled, purified water. Fractions $\mathrm{A}, \mathrm{B}$, and $\mathrm{C}$ were sterilized in an autoclave at $121^{\circ} \mathrm{C}$ for $20 \mathrm{~min}$ in separate containers, and then the temperature was adjusted to $45^{\circ} \mathrm{C}$ in a water bath. The fractions were then carefully combined with gentle swirling in the following order: fraction $\mathrm{A}$, (fraction $\mathrm{B}+$ fraction $\mathrm{C}$ ). Then the preparation was poured 
into sterile petri plates. The agar plates were dried overnight at room temperature under a vacuum in a desiccator that contained $\mathrm{CaCl}_{2}$ pellets. This medium was used to determine the aerotolerance of strain $\mathrm{HL}^{\mathrm{T}}$.

Characterization of strain $\mathrm{HL}^{\mathrm{T}}$. To determine growth and coprostanol production at various initial $\mathrm{pH}$ values, $\mathrm{BCM}$ was prepared; the $\mathrm{pH}$ was adjusted to 5.5 to 8.0 with $\mathrm{HCl}$ or $\mathrm{KOH}$, and $4 \mathrm{ml}$ was dispensed into each tube. A $1 \%$ inoculum of an overnight culture of strain $\mathrm{HL}^{\mathrm{T}}$ in $\mathrm{BCM}$ was added to each tube. After incubation for $18 \mathrm{~h}$ at $37^{\circ} \mathrm{C}$, the media were extracted, and the extracts were assayed by TLC (5). BCM was also prepared with each of the following buffers: $50 \mathrm{mM}$ acetate, $\mathrm{pH} 5.0 ; 50 \mathrm{mM}$ citrate-phosphate, $\mathrm{pH} 5.6 ; 50 \mathrm{mM}$ phosphate, $\mathrm{pH} 6.4$ and $7.2 ; 50 \mathrm{mM}$ Tris- $\mathrm{HCl}$, $\mathrm{pH}$ 7.6; and $50 \mathrm{mM}$ Tris- $\mathrm{HCl}, \mathrm{pH}$ 8.0. In addition, $\mathrm{BCM}$ was formulated to contain the following buffers (all obtained from Sigma): $10 \mathrm{mM}$ morpholineethanesulfonic acid (MES), $\mathrm{pH}$ $5.5 ; 10 \mathrm{mM}$ piperazine- $N, N^{\prime}$-bis(2-ethanesulfonic acid) (PIPES), $\mathrm{pH} 7.0$; and $10 \mathrm{mM} N$-[2-hydroxyethylpiperazine]$N^{\prime}$-[3-propanesulfonic acid] (EPPS), $\mathrm{pH}$ 8.0.

To determine the ability of strain $\mathrm{HL}^{\mathrm{T}}$ to grow in the absence of added cholesterol, BCM was prepared without cholesterol (BLEC medium). Strain $\mathrm{HL}^{\mathrm{T}}$ grown in BCM was inoculated into BLEC medium and serially 10 -fold diluted. After 1 week of incubation at $37^{\circ} \mathrm{C}$, the highest dilution that had a grainy appearance was transferred to fresh BLEC medium. Strain $\mathrm{HL}^{\mathrm{T}}$ was transferred 10 times in BLEC medium to confirm that it grew without cholesterol. The last subculture was inoculated into BCM, incubated for 3 days, and assayed for coprostanol production by TLC.

To determine phospholipase activity, 2-ml samples of strain $\mathrm{HL}^{\mathrm{T}}$ grown in BLEC medium were extracted with 3 $\mathrm{ml}$ of chloroform-methanol $(1: 1, \mathrm{vol} / \mathrm{vol})$. To detect phosphatidylcholine, silica gel TLC plates (type Si250-PA; J. T. Baker, Inc., Phillipsburg, N.J.) were spotted with 10- or $20-\mu l$ portions of sample. The plates were developed with chloroform-methanol-glacial acetic acid-water (100:56:20:10, $\mathrm{vol} / \mathrm{vol} / \mathrm{vol} / \mathrm{vol})$. To determine the presence of free fatty acids, TLC plates were developed with hexane-ethanolacetic acid (80:20:1, vol/vol/vol). Lipid spots were visualized with iodine vapors after overnight exposure in a sealed container. Permanent records of TLC plates were made by placing the developed plates on a clear glass plate positioned on a photoduplication machine.

The ability of strain $\mathrm{HL}^{\mathrm{T}}$ to grow in a cholesterol- and lecithin-free medium was determined by inoculating the bacterium into replicate tubes containing BCM prepared without cholesterol and lecithin. Cultures were transferred by using $1 \%$ inocula every 3 days five times, and the last subcultures were inoculated into BCM. After 1 week of incubation, the BCM broth cultures were observed for coagulation and assayed by TLC. The media tested included $\mathrm{BCM}$ without cholesterol and lecithin (B medium), and B medium containing $0.8 \%$ glycerol, $\mathrm{B}$ medium containing $1.0 \%$ lactose, $\mathrm{B}$ medium containing 0.02 or $0.5 \%$ sodium pyruvate, and B medium containing $0.05 \%$ sodium oleate plus $0.02 \%$ sodium pyruvate. Requirements for hemin and vitamin $\mathbf{K}_{1}$ were also determined by adding these compounds at the recommended concentrations (7).

Strain $\mathrm{HL}^{\mathrm{T}}$ was tested for reduction of nitrate; production of indole; hydrolysis of starch, gelatin, and esculin; and fermentation of amygdalin, L-arabinose, cellobiose, erythritol, fructose, glucose, glycogen, inositol, lactate, lactose, maltose, mannitol, mannose, melibiose, raffinose, L-rhamnose, D-ribose, salicin, soluble starch, sucrose, and D-xylose. Filter-sterilized solutions of substrates were added to sterile basal medium to obtain the final concentrations recommended by Holdeman et al. (7). The test media ( $4 \mathrm{ml}$ per tube) were inoculated with $0.1 \mathrm{ml}$ of strain $\mathrm{HL}^{\mathrm{T}}$ grown in $\mathrm{BCM}$. The cultures were incubated anaerobically at $37^{\circ} \mathrm{C}$ for 7 days, and then the $\mathrm{pH}$ values of the inoculated media were compared with the $\mathrm{pH}$ values of uninoculated controls. Reduction of nitrate, production of indole, and hydrolysis of starch, gelatin, and esculin were determined as described in the Anaerobe Laboratory Manual (7).

In addition to standard biochemical tests, strain $\mathrm{HL}^{\mathrm{T}}$ was evaluated by using the An-IDENT system (Analytab Products, Plainview, N.Y.) A bacterial suspension was obtained from 3-day-old cultures grown on MLA plates incubated in a GasPak jar (5). The procedures recommended by the manufacturer were used.

To determine $\mathrm{H}_{2}$ and $\mathrm{CO}_{2}$ production, media were dispensed $(20 \mathrm{ml}$ per tube) into tubes $(16$ by $150 \mathrm{~mm})$ sealed with rubber septum serum caps. BCM, BCM containing $0.5 \%$ glucose, $\mathrm{BCM}$ containing $0.5 \%$ sodium pyruvate, and $\mathrm{BCM}$ containing $0.5 \%$ lactose and $0.5 \%$ sodium pyruvate were prepared. The lactose, glucose, and pyruvate were added as filter-sterilized solutions made partly anaerobic by bubbling with Ar for $10 \mathrm{~min}$. A $1 \%$ inoculum of strain $\mathrm{HL}^{\mathrm{T}}$ was added to each tube, and the cultures were incubated at $37^{\circ} \mathrm{C}$ for 7 days. The headspace gas was analyzed with a series 580 gas chromatograph (Gow Mac, Bridgewater, N.J.) equipped with a thermal conductivity detector and a model 3393A integrator (Hewlett-Packard, Avondale, Pa.). Samples were removed from the culture tubes with a gas-tight syringe and injected into the sample loop $(0.5 \mathrm{ml}) . \mathrm{N}_{2}$ was the carrier gas for $\mathrm{H}_{2}$ determinations, and $\mathrm{He}$ was the carrier gas for $\mathrm{CO}_{2}$ determinations. The $\mathrm{H}_{2}$ and $\mathrm{CO}_{2}$ concentrations in the headspace gases of the cultures were compared with the concentrations in the headspace gases over uninoculated media.

To determine fermentation products, strain $\mathrm{HL}^{\mathrm{T}}$ was grown in BCM. This BCM culture was used to inoculate $\mathrm{BCM}, \mathrm{BCM}$ containing glucose, $\mathrm{BCM}$ containing pyruvate, and $\mathrm{BCM}$ containing lactose and pyruvate. We also prepared a subtracted growth medium similar to BCM containing lactose and pyruvate, except that the concentrations of lecithin, cholesterol, and $\mathrm{CaCl}_{2}$ were one-tenth the concentrations described above. After 4 days of incubation at $37^{\circ} \mathrm{C}$, the presence of butanol, ethanol, 2-propanol, methanol, and 1-propanol was determined by injecting culture liquid into a Hewlett-Packard model 5890 gas chromatograph equipped with a capillary column (5\% phenylmethyl silicone; $10 \mathrm{~m}$ by $0.53 \mathrm{~mm}$ by $2.65 \mu \mathrm{m}$ [film thickness]), a model $7673 \mathrm{~A}$ automatic sampler, a model HP3396 series II integrator, and a hydrogen flame ionization detector. The carrier gas was $\mathrm{N}_{2}$, and the column temperature was $40^{\circ} \mathrm{C}$. The formation of formic, acetic, propionic, butyric, caproic, fumaric, isobutyric, isovaleric, lactic, oxalic, phenylacetic, and succinic acids was determined by using the method of Salanitro and Muirhead (15). Butylated samples were analyzed with the same gas chromatograph system used to determine the presence of alcohols, except that the column temperature was increased $8^{\circ} \mathrm{C} / \mathrm{min}$ between 55 and $190^{\circ} \mathrm{C}$.

Aerotolerance was determined by incubating inoculated MLA plates in a GasPak jar for 5 days and then exposing the plates to air at room temperature. Isolated colonies were picked several times after exposure to air and were inoculated into BCM. After 1 week of incubation, the cultures were extracted and analyzed by TLC for coprostanol production. Strain $\mathrm{HL}^{\mathrm{T}}$ was also inoculated onto MLA plates placed in a candle jar, an evacuated vacuum jar, and air. 
After incubation at $37^{\circ} \mathrm{C}$ for 2 weeks, the plates were examined for growth.

DNA base composition. To determine the DNA $\mathrm{G}+\mathrm{C}$ content, E. coprostanoligenes DNA was isolated by the procedure of Jarrell et al. (8). The $\mathrm{G}+\mathrm{C}$ content was determined by the thermal denaturation method. (9).

Electron microscopy. A $200-\mathrm{ml}$ portion of subtracted growth medium containing lactose and pyruvate was inoculated with $2 \mathrm{ml}$ of a 1-day-old culture, and the preparation was incubated at $37^{\circ} \mathrm{C}$ for $48 \mathrm{~h}$. The bacteria were harvested by centrifugation at $10,000 \times g$ for $15 \mathrm{~min}$. The bacterial pellet was washed three times with $25 \mathrm{mM}$ PIPES buffer $(\mathrm{pH}$ 7.5) and then suspended in fresh buffer. The bacterial suspensions were fixed in $4 \%$ paraformaldehyde-3\% glutaraldehyde in $0.1 \mathrm{M}$ cacodylate buffer ( $\mathrm{pH} \mathrm{7.2)} \mathrm{overnight} \mathrm{at}$ $4^{\circ} \mathrm{C}$, washed three times in the same buffer, and postfixed in the same buffer containing $1 \%$ osmium tetroxide at $4^{\circ} \mathrm{C}$ for 1 h. The prepared cells were washed three times in buffer, placed in a microcentrifuge tube containing $1 \%$ agar (liquid), and pelleted. The pellet was dehydrated with a graded series of ethanol and embedded in LR White resin with constant agitation. The resin was polymerized overnight in a $65^{\circ} \mathrm{C}$ oven. Sections were cut with a Reichert Ultracut E ultramicrotome, placed on 200-mesh copper grids, poststained in a solution containing uranyl acetate and lead citrate, and viewed with a JEOL model $1200 \mathrm{EX}$ scanning transmission electron microscope operated at $80 \mathrm{kV}$.

\section{RESULTS}

Characterization of strain $\mathbf{H L}^{\mathbf{T}}$. Coprostanol production in unbuffered BCM preparations in which the initial $\mathrm{pH}$ was adjusted to various values was determined. The largest amounts of coprostanol were formed when the initial $\mathrm{pH}$ values were $7.0,7.2$, and 7.5; after incubation, the $\mathrm{pH}$ values of these media were $6.2,6.3$, and 6.4 , respectively. When the bacterium was grown in BCM containing organic or inorganic buffers, the greatest amount of coprostanol, as determined by the TLC assay, was produced at about $\mathrm{pH}$ 7.0. The amount of coprostanol produced at this $\mathrm{pH}$ was approximately the same as the amount produced at $\mathrm{pH} 7.2$ in BCM without a buffering system. After $48 \mathrm{~h}$, no coprostanol was produced in BCM buffered at $\mathrm{pH} 5.5$ with MES or at $\mathrm{pH} 8.0$ with EPPS.

When strain $\mathrm{HL}^{\mathrm{T}}$ was grown in BLEC medium (without cholesterol), growth was obvious because the medium assumed a grainy appearance. After the bacterium was transferred up to 10 times in BLEC medium, inoculation into $\mathrm{BCM}$ resulted in rapid and efficient cholesterol reduction; this finding indicated that strain $\mathrm{HL}^{\mathrm{T}}$ could grow in a cholesterol-free medium and that its cholesterol-reducing ability was retained in the absence of cholesterol. The results of TLC assays for phospholipase activity are shown in Fig. 1. When strain $\mathrm{HL}^{\mathrm{T}}$ was inoculated into BLEC medium, lecithin was metabolized, as shown by the disappearance of lecithin and the appearance of free fatty acids.

After several transfers in B medium (without cholesterol and lecithin), no growth (turbidity) was evident, and no growth or cholesterol reduction occurred when transfers were made into $\mathrm{BCM}$. Thus, strain $\mathrm{HL}^{\mathrm{T}}$ did not grow when both cholesterol and lecithin were omitted from the culture medium, even when the medium was supplemented with glycerol, lactose, pyruvate, oleate, hemin, or vitamin $K_{1}$.

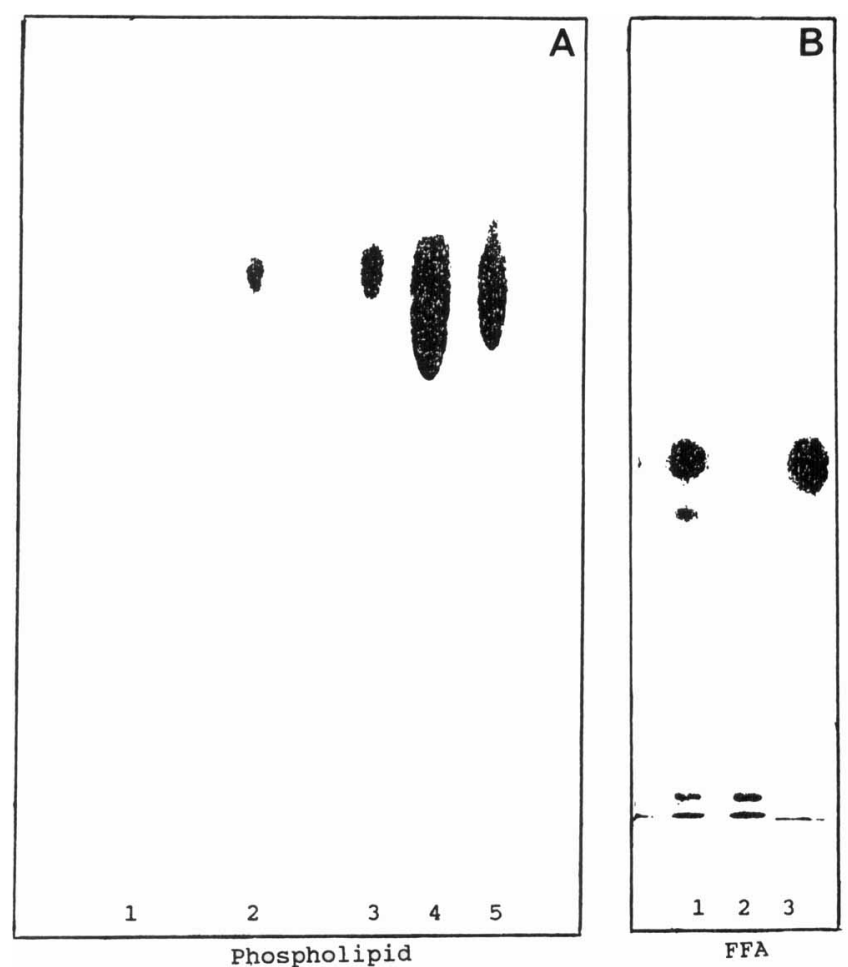

FIG. 1. Thin-layer chromatogram of phospholipids and free fatty acids (FFA) of strain $\mathrm{HL}^{\mathrm{T}}$ incubated for 1 day in BLEC medium. (A) Phospholipids. Lane 1, inoculated broth; lane 2, uninoculated broth; lane 3, lecithin ( $40 \%$ phosphatidylcholine); lane 4, 99\% pure phosphatidylcholine from soybeans; lane $5,99 \%$ pure phosphatidylcholine from egg yolks. (B) Free fatty acids. Lane 1, inoculated broth; lane 2, uninoculated broth; lane 3, oleic acid.

Strain $\mathrm{HL}^{\mathrm{T}}$ grew and reduced cholesterol in nitrate medium, but was negative for nitrate reduction. Indole was not produced. Starch and gelatin were not hydrolyzed. Esculin was hydrolyzed. Much acid (as defined in reference 7) was produced by the fermentation of amygdalin, lactose, and salicin. Strain $\mathrm{HL}^{\mathrm{T}}$ also weakly fermented L-arabinose, cellobiose, fructose, glucose, mannose, and melibiose. The $\mathrm{pH}$ of the basal medium containing no added carbohydrates also decreased from an average value of 6.95 to an average value of 6.18 .

When strain $\mathrm{HL}^{\mathrm{T}}$ was tested by using the An-IDENT system, positive reactions for $\beta$-glucosidase activity and hydrolysis of indoxylacetate were observed. All other tests were negative.

The percentages of the headspace gas volumes occupied by the $\mathrm{H}_{2}$ and $\mathrm{CO}_{2}$ produced by strain $\mathrm{HL}^{\mathbf{T}}$ in various media ranged from 4.5 to $7.2 \%$ and from 0.9 to $1.8 \%$, respectively. Production of $\mathrm{CO}_{2}$ did not significantly increase when pyruvate was added to the growth medium. The amounts of acetic acid produced ranged from 0.105 to $1.079 \mathrm{meq} / 100 \mathrm{ml}$. The amounts of formic acid produced ranged from 0 to 0.196 meq/100 ml, and the amounts of succinic acid produced ranged from 0.027 to $0.392 \mathrm{meq} / 100 \mathrm{ml}$. No alcohols were produced.

Strain $\mathrm{HL}^{\mathrm{T}}$ survived exposure to air for up to $48 \mathrm{~h}$. No growth was observed on inoculated MLA plates incubated in a candle jar, in an evacuated vacuum jar, or in air.

Electron micrographs of strain $\mathrm{HL}^{\mathrm{T}}$ (Fig. 2) revealed the presence of coccobacilli that were about 0.5 to $0.7 \mu \mathrm{m}$ long. 


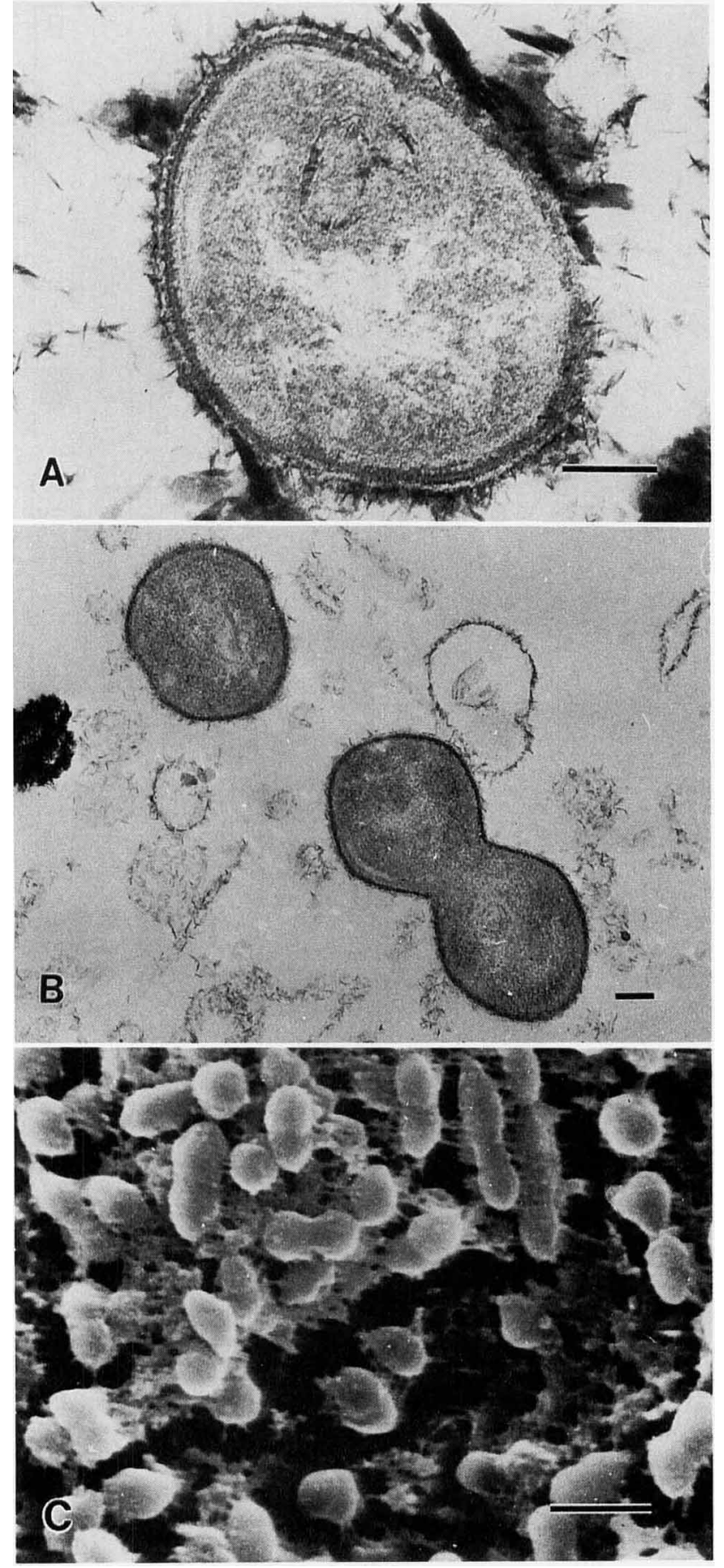

FIG. 2. Electron photomicrographs of strain $\mathrm{HL}^{\mathrm{T}}$. (A) Bar $=0.1$ $\mu \mathrm{m}$. (B) Bar $=0.2 \mu \mathrm{m}$. (C) Bar $=1.0 \mu \mathrm{m}$.

Thus, strain $\mathrm{HL}^{\mathrm{T}}$ cells are shorter than the cells of most Eubacterium spp. (10). The DNA of strain $\mathrm{HL}^{\mathrm{T}}$ has a $\mathrm{G}+\mathrm{C}$ content of $41 \mathrm{~mol} \%$.

\section{DISCUSSION}

Mott and Brinkley (12) observed that most of the previously isolated strains of cholesterol-reducing bacteria required plasmenylethanolamine to reduce cholesterol to coprostanol. These authors determined that the plasmalogen was metabolized to undescribed end products, as shown by its disappearance from the growth medium. They also observed that Eubacterium sp. strain ATCC 21408 (4) had sphingomyelinase activity, but none or the metabolites of sphingomyelin supported growth of the bacterium (12). The ways in which phospholipase and sphingomyelinase activities are related to cholesterol reduction are not known. One possibility is that these compounds or their metabolites alter the bacterial membrane, increasing the accessibility of the cholesterol to cholesterol reductase. These compounds also may affect the micelle structure in which the cholesterol is imbedded and thus increase the availability of cholesterol.

When glycerol or free fatty acids were added along with cholesterol to a basal medium, strain $\mathrm{HL}^{\mathrm{T}}$ did not grow or reduce cholesterol, although growth occurred in the presence of phosphatidylcholine. This observation suggests that enzymatic hydrolysis of phosphatidylcholine is necessary for growth (and cholesterol reduction?). Calcium chloride stimulated coprostanol formation by strain $\mathrm{HL}^{\mathrm{T}}(6)$. The phospholipid substrate must have a net positive charge for enzymatic action by phospholipase C (13). Accordingly, the positive charge is supplied by added $\mathrm{Ca}^{2+}$, which functions as an activator of phospholipase $\mathrm{C}$. The subsequent hydrolysis of phosphatidylcholine may provide a cofactor or may act directly in coprostanol formation. These questions will be answered more easily when cell-free cholesterol reductase preparations become available.

Brinkley and coworkers (1) reported that several strains of cholesterol-reducing bacteria could grow on supplemented brain heart infusion agar plates incubated in an anaerobic chamber. When the strains were subcultured repeatedly, they retained their ability to reduce cholesterol. However, when we plated strain $\mathrm{HL}^{\mathrm{T}}$ on the same medium used by Brinkley et al. (1) and incubated the plates in a GasPak jar, no growth was observed. MLA prepared without cholesterol (but with lecithin), however, did support growth of strain $\mathrm{HL}^{\mathbf{T}}$, and the colonies were similar in appearance to colonies on MLA containing cholesterol (6). The requirement for lecithin for colony formation may be unique to strain $\mathrm{HL}^{\mathrm{T}}$.

Strain $\mathrm{HL}^{\mathrm{T}}$ grew and retained its cholesterol-reducing ability after 10 transfers in BLEC (cholesterol-free) medium. A very minute amount of a phytosterol with a structure similar to that of cholesterol may have been present in the crude soybean lecithin used in BLEC medium. However, no sterol with the retention value of cholesterol was detected in a TLC assay of BLEC medium. The TLC assay used was sufficiently sensitive to detect approximately $20 \mu \mathrm{g}$ of sterol per ml of culture medium (6). The amount of cholesterol or phytosterol that may have been present in the crude lecithin was well below the $1 \mathrm{mg} / \mathrm{ml}$ required for the maintainence of Eubacterium sp. strain ATCC 21408 (4).

Strain $\mathrm{HL}^{\mathrm{T}}$ closely resembles other members of the genus Eubacterium. Several members of this genus have steroidmetabolizing activities, including 7-hydroxylase, 7- and 21dehydroxylase, 7- and 20-hydroxysteroid dehydrogenase, 16-dehydroxylase-reductase, progesterone delta-4 reductase, 3-dehydroxylase, and desmolase (reviewed in reference 5). However, these activities have been shown to be very specific, and evidence for the reduction of cholesterol to coprostanol remains limited to the previously mentioned 13 strains of Eubacterium species. Strain $\mathrm{HL}^{\mathrm{T}}$ cannot be classified as Eubacterium lentum because growth was not stimulated by arginine, it did not fluoresce red under UV light (11), and it did ferment carbohydrates.

Strain $\mathrm{HL}^{\mathrm{T}}$ seems quite similar to strains 103 and 104 , 
which were isolated by Brinkley et al. (1) and were classified as Eubacterium sp. These strains had carbohydrate fermentation patterns somewhat similar to that of strain $\mathrm{HL}^{\mathrm{T}}$, produced $\beta$-glucosidase, hydrolyzed esculin, and metabolized pyruvate. Strains 103,104 , and $\mathrm{HL}^{\mathrm{T}}$ all produced acetic and succinic acids.

Despite the fact that strains 103,104 , and $\mathrm{HL}^{\mathrm{T}}$ have several characteristics in common, strain $\mathrm{HL}^{\mathbf{T}}$ also differs significantly from strains 103 and 104. Strains 103 and 104 grew on supplemented brain heart infusion agar plates without cholesterol or lecithin (1), whereas strain $\mathrm{HL}^{\mathrm{T}}$ did not grow in the absence of lecithin. Strains 103 and 104 reduced cholesterol to coprostanol in the absence of plasmalogen but were tested only in media containing both cholesterol and lecithin. The requirement of lecithin for cholesterol reduction and the presence of phospholipase activity were not tested in strains 103 and 104 . Strains 103 and 104 produced from 1 to $11 \% \mathrm{CO}_{2}$ in the headspace gas of brain medium and from 9 to $20 \% \mathrm{CO}_{2}$ in the headspace gas of brain medium supplemented with pyruvate; no $\mathrm{H}_{2}$ was produced (1). Thus, these strains differed in metabolism from strain $\mathrm{HL}^{\mathrm{T}}$, which produced approximately $1 \% \mathrm{CO}_{2}(\mathrm{a}$ value that did not increase when pyruvate was added) and up to approximately $7 \% \mathrm{H}_{2}$. Strain $\mathrm{HL}^{\mathrm{T}}$ also differed from strains 103 and 104 in the production of formate, although the methods used by Brinkley and Mott (2) may not have detected formate production.

Another possible difference between strains 103 and 104 and strain $\mathrm{HL}^{\mathrm{T}}$ is the aerotolerance of these organisms. Strain $\mathrm{HL}^{\mathrm{T}}$ required anaerobic conditions to grow but survived long exposures to atmospheric oxygen. Unfortunately, data on the aerotolerance of strains 103 and 104 were not published, and the strains were not available for comparison. Strain $\mathrm{HL}^{\mathrm{T}}$ was negative for catalase activity, and how this bacterium is protected from oxygen merits further study.

Lower levels of acetic and succinic acids were produced in a medium containing $0.2 \mathrm{mg}$ of cholesterol per $\mathrm{ml}$ (subtracted growth medium containing lactose and pyruvate) than in a medium containing $2.0 \mathrm{mg}$ of cholesterol per $\mathrm{ml}$ (BCM containing lactose and pyruvate). This difference may have been caused by stimulation of the metabolism of strain $\mathrm{HL}^{\mathrm{T}}$ by cholesterol or by an increase in cell numbers in the presence of increased cholesterol concentrations.

When sodium pyruvate was present in the growth medium, strain $\mathrm{HL}^{\mathrm{T}}$ produced significantly more acetic acid than it produced in media without pyruvate, whereas the amounts of formic acid and succinic acid remained approximately the same. Pyruvate was metabolized by strain $\mathrm{HL}^{\mathrm{T}}$ because it disappeared from the growth medium (data not shown). Perhaps pyruvate acts directly as a cofactor in cholesterol reduction. Other workers have reported a similar observation; pyruvate acted as an electron donor for 16dehydroprogesterone reductase in cell extracts of Eubacterium sp. strain 144 (16). More definitive data on the interrelationships of pyruvate and cholesterol reductase will become available when activity can be assayed in cell extracts.

Description of Eubacterium coprostanoligenes sp. nov. Eubacterium coprostanoligenes (co.pro.stan.ol. $\mathrm{i}^{\prime}$ gen.es. L. adj. coprostanoligenes, producing coprostanol). The coccobacilloid cells are 0.5 to $0.7 \mu \mathrm{m}$ in diameter and 0.7 to $1.0 \mu \mathrm{m}$ long and occur singly and in pairs. The cells are nonmotile, gram positive, and non-spore forming. Surface colonies on anaerobic MLA plates are small, white, and circular with a powdery texture. Growth and coprostanol production are optimal at $\mathrm{pH} 7.0$ to 7.5 and $35^{\circ} \mathrm{C}$. Growth and coprostanol production do not occur at $\mathrm{pH} 5.5$ or 8.0 or at incubation temperatures of 25 or $45^{\circ} \mathrm{C}$.

Aerotolerant anaerobic chemoorganotroph. Phosphatidylcholine is metabolized and is required for growth. Cholesterol is reduced to coprostanol, but is not required for growth. Nitrate is not reduced, and indole is not produced. Starch and gelatin are not hydrolyzed. Esculin and indoxylacetate are hydrolyzed, and cells produce $\beta$-glucosidase. Much acid is produced by the fermentation of amygdalin, lactose, and salicin. L-Arabinose, cellobiose, fructose, glucose, mannose, and melibiose are weakly fermented. Moderate amounts of $\mathrm{H}_{2}$ and small amounts of $\mathrm{CO}_{2}$ are produced. Acetic, formic, and succinic acids are produced. No alcohols are produced.

The DNA of the type strain, strain $\mathrm{HL}$, has a $\mathrm{G}+\mathrm{C}$ content of $41 \mathrm{~mol} \%$. This bacterium was isolated from anoxic material from a hog sewage lagoon in Ames, Iowa. Strain $\mathrm{HL}^{\mathrm{T}}$ has been deposited in the American Type Culture Collection, Rockville, Md., as strain ATCC $51222^{\mathrm{T}}$.

\section{ACKNOWLEDGMENTS}

This study was supported by a grant from the Wisconsin Milk Marketing Board and by the Iowa Agriculture and Home Economics Experiment Station (projects 2678 and 3042).

The skilled technical assistance of Eureka Pickett was greatly appreciated. We also thank Herb Cook for his assistance in the gas chromatography analysis and Nancy Cornick for her assistance in the $\mathrm{G}+\mathrm{C}$ determination. The electron microscopy was done at the Bessey Microscope Facility, Department of Botany, Iowa State University.

\section{REFERENCES}

1. Brinkley, A. W., A. R. Gottesman, and G. E. Mott. 1982. Isolation and characterization of new strains of cholesterol-reducing bacteria from baboons. Appl. Environ. Microbiol. 43:86-89.

2. Brinkley, A. W., and G. E. Mott. 1978. Anaerobic fecal bacteria of the baboon. Appl. Environ. Microbiol. 36:530-532.

3. Chrisope, G. L., C. W. Fox, and R. T. Marshall. 1976. Lecithin agar for detection of microbial phospholipases. Appl. Environ. Microbiol. 31:784-786.

4. Eyssen, H. J., G. G. Parmentier, F. C. Compernolle, G. De Pauw, and M. Piessens-Denef. 1973. Biohydrogenation of sterols by Eubacterium ATCC 21,408-nova species. Eur. J. Biochem. 36:411-421.

5. Freier, T. A. 1991. Ph.D. thesis. Iowa State University, Ames.

6. Freier, T. A., D. C. Beitz, L. Li, and P. A. Hartman. Unpublished data.

7. Holdeman, L. V., E. P. Cato, and W. E. C. Moore (ed.). 1977. Anaerobe laboratory manual. Virginia Polytechnic Institute and State University Anaerobe Laboratory, Blacksburg.

8. Jarrell, K. F., D. Faguy, A. M. Hebert, and M. L. Kalmokoff. 1992. A general method of isolating high molecular weight DNA from methanogenic archaea (archaebacteria). Can. J. Microbiol. 38:65-68.

9. Mandel, M., and J. Marmur. 1968. Use of ultraviolet absorbance-temperature profile for determining the guanine plus cytosine content of DNA. Methods Enzymol. 12B:195-206.

10. Moore, W. E. C., and L. V. Holdeman Moore. 1986. Genus Eubacterium, p. 1353-1373. In P. H. A. Sneath, N. S. Mair, M. E. Sharpe, and J. G. Holt (ed.), Bergey's manual of systematic bacteriology, vol. 2. The Williams \& Wilkins Co., Baltimore.

11. Mosca, A., C. A. Strong, and S. M. Finegold. 1993. UV red fluorescence of Eubacterium lentum. J. Clin. Microbiol. 31: 1001-1002.

12. Mott, G. E., and A. W. Brinkley. 1979. Plasmenylethanolamine: growth factor for cholesterol-reducing Eubacterium. J. Bacteriol. 139:755-760.

13. Ottolenghi, A. O. 1967. Cationic antibiotics and phospholipase $C$ as tools in the study of phospholipid structure and function. II. 
Can. J. Biochem. 45:245-256.

14. Sadzikowski, M. R., J. F. Sperry, and T. D. Wilkins. 1977. Cholesterol-reducing bacterium from human feces. Appl. Environ. Microbiol. 34:355-362.

15. Salanitro, J. P., and P. A. Muirhead. 1975. Quantitative method for the gas chromatographic analysis of short-chain monocar- boxylic and dicarboxylic acids in fermentation media. Appl. Microbiol. 29:374-381.

16. Watkins, W. E., and T. L. Glass. 1991. Characteristics of 16-dehydroprogesterone reductase in cell extracts of the intestinal anaerobe, Eubacterium sp. strain 144. J. Steroid Biochem. 38:257-263. 